Iris Schaller-Schwaner

\title{
Does a picture say more than 7000 words? Windows of opportunity to learn languages - an attempt at a creative reflective poster
}

\begin{abstract}
This article originated in a creative attempt to engage audiences visually, on a poster, with ideas about language(s), teaching and learning which have been informing language education at university language centres. It was originally locally grounded and devised to take soundings with colleagues and with participants at the CercleS 2014 Conference hosted at the University of Fribourg. It uses a local campus building as a reflective canvas, as it were. Simultaneously, it deals with concepts of wider currency which may influence and engage language teachers' awareness and practices in other tertiary contexts. The poster's visual appeal not only contrasts with the linearity of academic writing but its open-endedness creates a space for exchange and discussion. It also creates a space for theory, which few practitioners will engage with of their own accord. The poster's inherent dimension of interpretation by the viewer extends an invitation to respond. This article may render its content more tangible or accessible through verbal elaboration that complements the visual. The notions and cognitions discussed include reflection(s), languaging, a language formula, the Indo-European tree of languages, a multilingual linguistic sign, Douglas Adams's Babel fish, the IPA vowel quadrilateral, a syntactic tree, and a pyramid of learning. Presenting this poster and article to a wider audience can be framed as a novel dialogue and dialectic about conceptualisations that are influential for university language teaching. It is also an unorthodox way of approaching theory didactically and with language teacher cognitions (Borg 2009) in mind, and a means of stimulating engagement with multilingualism.
\end{abstract}

Key words: reflective practice, communicating foreign language teaching (theory), language conceptualisations, teacher cognitions, ideas about multilingualism

DOI 10.1515/cercles-2015-0001

Iris Schaller-Schwaner, University of Fribourg Language Centre, Rue de Rome 1, CH-1700

Fribourg, Switzerland, E-mail: Iris.Schaller-Schwaner@unifr.ch 


\section{Introduction}

The purpose of this article is to explain a poster which was devised to draw attention to university language teaching at the University of Fribourg Language Centre, the host of the CercleS 2014 Conference. To kindle curiosity and trigger responses, clues to questions and issues are provided, but no definitive answers. The preliminary considerations, outlined below, invite readers to respond, modify, refute, and extend the development of disciplinary thinking beyond one conference. The poster is shown in its entirety in Figure 1; selected details are discussed in the successive sections of the article.

The poster visually articulates a number of popular and theoretical notions about language, but in as language-independent a manner as possible. It provides more graphic shapes than metalanguage to provoke reflection about conceptualisations of language as an object and an activity, and also about how ideas have been evolving in our field. As a poster for a university language centre, as an advertisement for the teaching and learning of languages to promote or enhance academic plurilingualism, and as an illustration of the disciplinary background we draw on and the autonomous applied field that we are, the photograph of a building might raise eyebrows. What it is meant to raise, however, is issues, awareness and discussion about what it is that we teach, learn and promote, and how far the mono-, bi- and multilingual context is a determining element in the individual's language development. Both folk and academic ideas about what language is, how languages work, and what plurilingualism means have a considerable impact on how languages are used, evaluated (in terms of general opinions held), taught, and learned, but this is not always acknowledged. Language lecturers often foreground practical aspects of their work. However, university language teaching, like many other academic fields that have a "clinical" aspect, is not merely an art and a craft; it is also a reflective practice, an area of principled inquiry, and a philosophy (Rajagopalan 2003). Thus it is worth recalling one of Stern's (1983) Fundamental concepts of language teaching, namely that every language teacher and every language learner has their own ideas or cognitions about what it is that they want to teach or learn. In this sense, we all have implicit theories about language and languages, theories with a small t. Concerning theories with a capital $\mathrm{T}$, reflecting on and critically examining metaphors and abstractions is a way forward in many areas, helping to explain complexities in more familiar terms or to de-familiarize the familiar as an object of examination. 


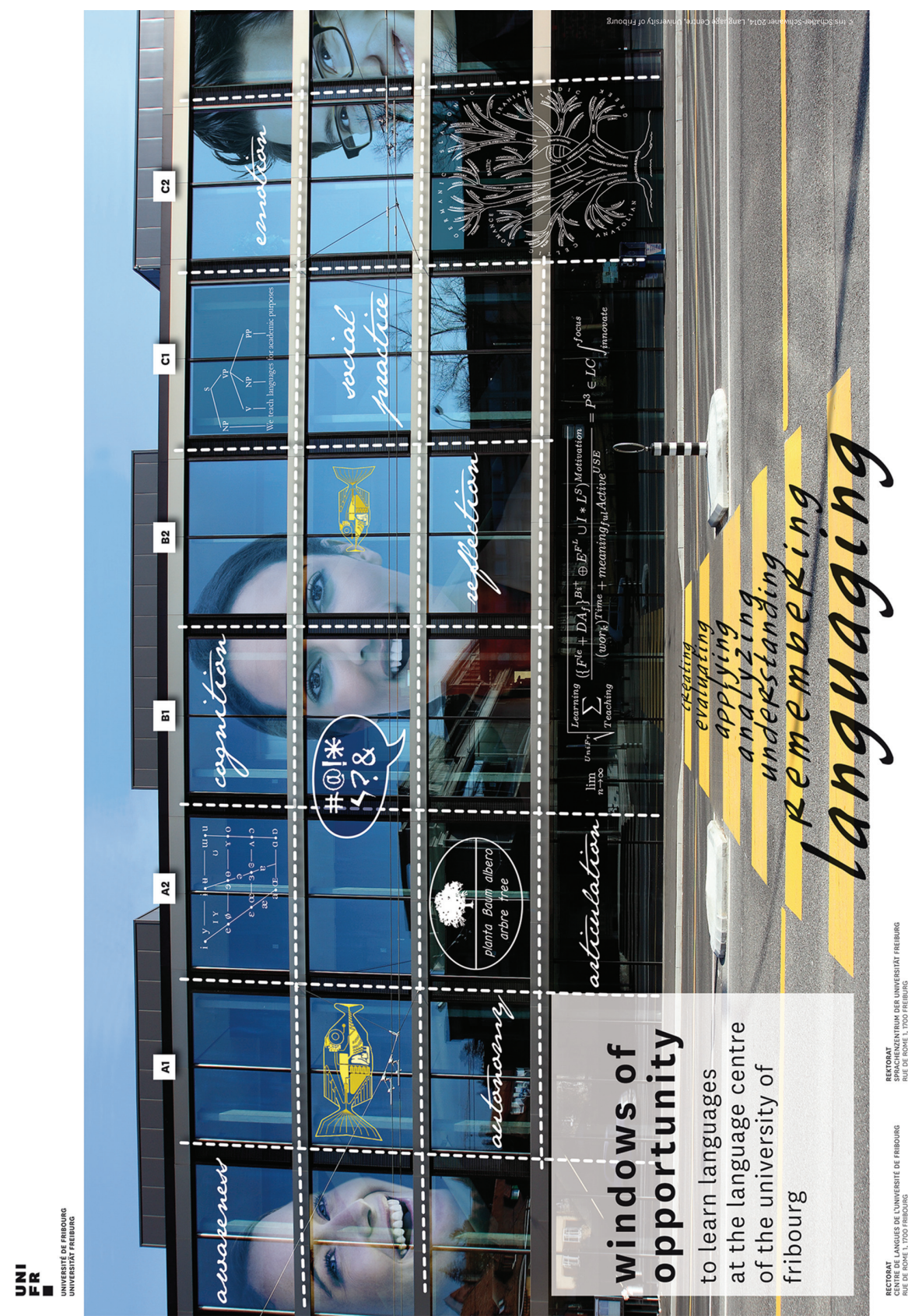




\section{Reflections}

Reflection is polysemous, suggesting both an image in a mirror or on a shiny surface and also considered written or spoken thoughts about a particular topic. The most salient feature of the façade of the campus building in Figure 1 is reflecting glass. Walking by or crossing towards it, reflection effects become ever more prominent. A mirror image confirms one's presence in a place, invites one to enter, and even creates a faint sense of feeling at home. Because anyone who approaches can see themselves in the language centre, as it were, the central message of our shiny windows is the appeal of the mirror image: a signal of attention to and focus on the individual, our learner-centeredness and our concern with learner needs and agency, which will vary with individuals' plurilingual profiles and purposes. Instead of viewers seeing themselves, one sees three faces looking in and looking out, soon to orient themselves towards each other. They represent the social aspect of language use, language as a social practice, and consequently also language learning as a sociocultural activity in which one is exposed to a language to be learned as a social practice of meaning making, a coconstructed practice to participate in actively, productively, and with increasing fluency, complexity and accuracy (e.g. Larsen-Freeman 2009; Pallotti 2009). Windows of opportunity for becoming functionally plurilingual might open in many contexts in higher education, but the university language centre is where such opportunities are purposefully offered and where one can seek specialist support, provided one is willing to engage in the process of expanding or maintaining one's plurilingual repertoire. In short, it is a place with and for people who need, want, have and use more than one language in their social and academic lives at university. The experience of languaging (cf. below) is what makes the additional languages tangible for the learner.

There is at least one more sense in which the building's glass front makes sense and provides a focus for discussion about university language centres. The linguist Wallace Chafe (1994: 38) used the image of a pane of glass when he argued that while language users do not normally see the glass, i.e. the linguistic form, through which their ideas pass when they express themselves, linguists are trained to see this pane of glass. It takes an act of will not to focus on the ideas. At the same time, for many additional language users who are learning, studying in or teaching a language that has not always been in their repertoire, the idea that linguistic form can be transparent to the point of invisibility must seem to belong to a naïve monolingual habitus (Gogolin 1994, 1998). They are more often than not highly aware of the glass. The enhanced language awareness typically engendered in multilinguals (Jessner 2006) is in daily evidence. 
In a certain sense, we are concerned with linguistic form all the time, in our effort to make sure our ideas become transparent in the first place. Some language professionals can become so concerned with perceived language norms that it may even take a special act of will to focus on the ideas expressed. However, preoccupation with focus on form may eclipse content to an extent that demotivates language learners who are interested in content expressed through the target language. Arguably, a focus on the ideas expressed is what functional plurilingualism and communicative, task-oriented or specific-purpose language use and language teaching may at times require e.g. to promote fluency, a particular interactional goal or oral confidence.

Looking at the reflections on the glass front one more time, one also perceives the main university building of the local Miséricorde campus, reminding us first that language learning is embedded in a context of university studies and of continuous language socialisation, and second that learning additional languages does not take place on a tabula rasa. Previously acquired language(s) and earlier language learning experiences will always be reflected in the ways we expand and use our plurilingual repertoires. In this particular case, one must bear in mind that the Université de Fribourg/Universität Freiburg is a bilingual university in three distinct senses: (i) a parallel, (ii) a complementary and (iii) an integrative sense (cf. Brohy 2005). First, as UniFr is located in a Swiss canton with two official languages, most faculties offer parallel monolingual studies in German and French. Second, to promote (the development of) individual bilingualism, options to take courses in both languages have been developed and promoted over the past two decades, and there are now also some Englishmedium and trilingual options for master's programmes. Third, it is not always possible to choose between French- and German-medium programmes: some courses are available in only one of the two languages (or sometimes English) and students have to cope at least receptively. This situation occurs most frequently in the science faculty, where integrative bilingual bachelor's programmes can only be followed up by master's programmes taught primarily in English (or in all three languages). Disciplinary socialisation in the sciences thus always comprises an additional language (cf. Schaller-Schwaner 2011, 2012).

Now, let me take a look at the building's structure as a whole and the allusion to the CEFR, which is represented through the labels on the roof and the broken lines between the window panes. The CEFR is so much a given that it cannot be avoided, but at times there is a tendency for us to forget that it too is an abstraction, a metaphor, a tool to be used when appropriate, and not the phenomenon itself, whose fuzziness, blur and vagueness are important functionally and descriptively (see, e.g., Butterfield 2012). In making development and progress somewhat more tangible and operationalizing differential abilities 
descriptively, one can both clarify and obscure what is involved in the effortful process of learning and teaching additional languages. Much as a framework can support and enhance through delineation, it can also express our ideas and understandings of a dynamic phenomenon in static terms and become limiting. In this sense, interrogating some of the notions or short-hand expressions that have sprung from the CEFR could be a healthy and necessary part of using it. For example, should we really be talking about teaching levels, instead of teaching languages or teaching people?

\section{Languaging as the basis}

The use of language as a verb in language teaching contexts was first proposed by Merrill Swain to emphasize that language use is an activity that plays an essential role in effective learning. She uses languaging to refer to the cognitive processes of negotiating and producing meaningful, comprehensible output as a part of language learning. Drawing on Vygotskian insights into the mediating function of language for many mental activities, i.e. language as a tool of the mind in many or most knowledge and skill domains, she argues that higher cognition, learning and talking to oneself and others (or writing) are inextricably linked and that languaging strengthens learner agency. Languaging is "the process of making meaning and shaping knowledge and experience through language" (Swain 2006: 98). Languaging is thus a prerequisite for many kinds of learning, but she also argues that languaging about languaging is what takes us to advanced levels in learning additional languages (e.g. Swain et al. 2009).

The pedestrian crossing that leads towards the building (cf. Figure 1) is used in the poster to allude to a famous pyramid of learning, more or less in a shape familiar as a revised version of Bloom's (1956) Cognitive Taxonomy, which originally used the nouns knowledge, comprehension, application, analysis, synthesis and evaluation and did not include creating, which was added later (Anderson \& Sosniak 1994). Inspired by Smith (2014), an essential new base, languaging, has been added to the triangle of words on the pedestrian crossing. ${ }^{1}$ Despite its age, Bloom's Taxonomy is still popular in the age of e-learning, and the active verbs associated with each stage of learning are not unlike the ones used to describe learning outcomes for university courses under the Bologna

1 I discovered the idea of adding something as a new base to the triangle (i.e. pyramid) made for Bloom's Taxonomy on a blog http://eltcriticalmoments.wordpress.com/2014/01/05/the-flippedpyramid-and-the-snaggle-toothed-edifice/ posted on January 5, 2014 on Tom Smith's website http://eltcriticalmoments.wordpress.com/ 
scheme. However, what is left implicit or even taken for granted more often than not, is the linguistic aspect of the medium of instruction and the basis of all these increasingly sophisticated forms of learning. Notwithstanding the variable extent to which academic disciplines depend on language, languaging is the foundation of it all, the sine qua non of defining, repeating, explaining, interpreting, differentiating, appraising, debating, composing or critiquing. In a multilingual academic context it becomes apparent how access to learning begins with access to the languages in which teaching takes place. Once again, it seems to be a form of monolingual-habitus (Gogolin 1994, 1998) myopia, also encountered in plurilinguals, to ignore this: only if a single language is available can one take it for granted as the default medium and the 'unmarked case'. If however languaging is the basis of most learning and teaching at university and if one language is not enough for all purposes in a multilingual academic context, then support should be provided at the university language centre. It is a place for teaching and learning additional languages; a place of guided or independent autonomous study, of applied research and reflective practice; a place of materials development, participation in projects, and testing/assessment; and, once again, most of all it is a place with people and for people who need, want, have and use (resources from) more than one language in their diverse social and academic lives in the university and beyond. Certainly, our concept of languaging needs to take into account plurilanguaging and translanguaging (Li Wei 2011) as ways of participating in some practices, but without excluding lingua franca use, as converging on a single additional language will be essential in other settings. As I have pointed out elsewhere (Schaller-Schwaner 2011), the use of English as a lingua franca in multilingual academic contexts can also be regarded as a plurilingual practice. In this vein, the use of English on the poster is an opportunity to reconceptualise and expand on what we mean by plurilingualism. Established conceptualisations of plurilingual practices require more than one language on the linguistic surface (code-switching, language alternation). Where this is unrealistic or not the intention, however, such as at an international conference, "code-sharing" lingua franca mode (Schaller-Schwaner 2011) in one language may be regarded as an alternative or preferred plurilingual practice: everybody uses the same additional language in order to sustain disciplinary exchange.

\section{A formula}

In the case of this particular university language centre, the pedestrian crossing leads us to a representation of its language teaching focus, making use of 
mathematical symbols to express (inadequately) the variable and dynamic outcomes of our daily endeavour to promote plurilingualism. The formula (see Figure 2), inspired by Scott Douglas's additional language acquisition formula (Douglas 2013) on his blog at http://englishforacademicpurposes.blogspot.ch/, is more self-promotional than self-ironical and has many variables missing. It implies the neatness of mathematics where messiness or chaos-complexity are much more realistic notions, but it is nevertheless designed to express the dynamic of teaching and learning languages in a university setting in which four languages, not one, play an important role as territorial or specific-purpose local academic languages.

$$
\lim _{n \rightarrow \infty} \sqrt[U n i F r]{\sum_{\text {Teaching }}^{\text {Learning }} \frac{\left(\left\{F^{l e}+D A_{f}\right\}^{B i^{+}} \oplus E^{F^{L}} \cup I * L^{S}\right)^{\text {Motivation }}}{\left(\text { wor }_{k}\right)^{\text {Time }}+\text { meaning }}}=P^{3} \in L C \int_{\text {innovate }}^{\text {Active }} \text { fSE }
$$

Figure 2: A language formula.

The formula shows the root of UniFr language learning and teaching as the sum total of French as a foreign language (FLE) plus German as a foreign language (DAF) in curly brackets to the power of $\mathrm{Bi}+$ (Bilingue plus, a special programme in French and German) plus English as a foreign language (EFL) as well as Italian as a foreign language (ILS), to the power of motivation, divided by work over time and meaningful active language use. Let this be equal to P cubed, i.e. plurilingual practices and profiles emerging at the language centre, the integral of focused language work and innovation: in teaching, (supported) autonomous language learning of many other languages, and applied research.

Since heretics used to be punished on the site of today's university campus Miséricorde, let me clarify the point of the formula. In a sense, it is a crude oversimplification, a playful idealisation; some might argue that it is a naïve fallacy: one cannot add up languages to produce plurilingualism. But do we all really know this and understand the implications? Knowledge construction in a domain can start out from a falsification, and perhaps this is how models of multilingual language teaching and plurilingualism may eventually be derived, beginning with an initially flawed abstraction, a formula in need of revision. Among extant abstractions, Herdina \& Jessner's (2002) dynamic model of multilingualism, based on dynamic systems theory, stands out as a sophisticated example from psycholinguistics.

The second and more pragmatic purpose of the formula is to be different, to function as an attention grabber. It intends to draw attention to those learners who do not love foreign languages, who customarily question their linguistic 
talents, not seeing themselves as gifted in foreign languages, and who have profited least, in terms of oral communicative competence in an additional language, from earlier orthodoxies of foreign language teaching such as translation, reading literary classics in the target language, and writing essays on literary topics. When they choose to study natural sciences at the University of Fribourg they realize that languaging in the partner language or in a third language ${ }^{2}$ is required at least receptively in order to learn about their subject. This is a situation that occurs whenever the medium of instruction is not the student's default or preferred language. These students may be the ones who need language teaching for specific purposes most and from whom we have most to learn when we help them to work in multilingual teams or tell their research stories in additional languages. What they need for this in addition to the language of formulae is natural language skills, but for their specific academic purposes.

\section{The Indo-European language family tree}

To the right of the formula, among the bare trees reflected in the glass front, we find another, equally bold but much more organic, abstraction, a representation of August Schleicher's (died 1868) family tree of Indo-European languages (found in Pennisi 2004; after Gamkrelidze \& Ivanov 1990: 111). Despite its venerable age and ideological baggage (e.g. Hutton 2014) it still captures facts about similarities between many European and non-European languages in terms of development and divergence from a common root and stem (e.g. Fischer 2010).

It is based on historical, reconstructive contrastive linguistic work and explains why there are so many similarities, for instance, among the Romance languages and among the Germanic languages but hardly any between them and Finnish, which is not an Indo-European language. On the whole, intercomprehension and language learning within a group of daughter languages can be eased initially. However, facilitative effects may not be bidirectional (between languages) and facilitation of learning may not last, while unrelatedness and dissimilarity between languages do not necessarily

2 As an (economically conditioned) exemplar of integrative 'bi(tri)lingualism' (cf. above; Brohy 2005; Schaller-Schwaner 2011: 425f), the local science faculty requires students to understand course content regardless of the medium in which a course happens to be taught (mostly French or German at bachelor's level while master's programmes are principally taught in English or in all three languages). 


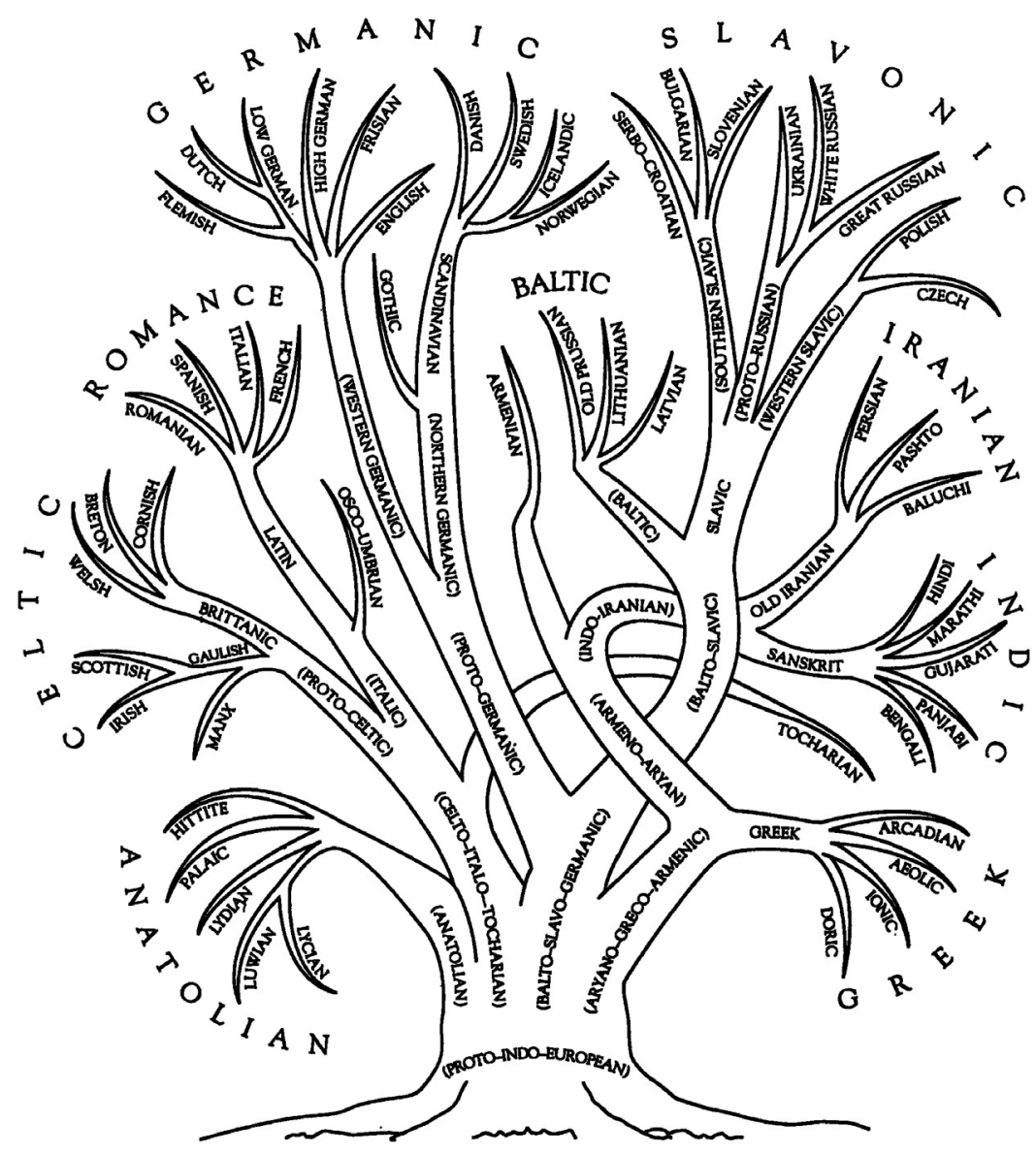

Figure 3: Indo-European family tree.

lead to learning difficulty: different does not always mean difficult (Kaiser et al. 2014). The complexity of these relationships helps to explain why the contrastive hypothesis of SLA, in its narrow sense, proved untenable. However, the tree metaphor is not only organic but also a social metaphor in that it combines linguistic relatedness with conceptualisations of kinship and genealogy: the idea of language families, of mother and daughter languages. The way languages change over generations in this model also reflects on an issue that is very close to the heart of many language users and language teachers in multilingual contexts, the issue of language purity. As Mufwene (2001) points 
out, there are no father languages in this genealogical/genetic model, no hybridity, and apparently no language contact. It does not explain why there are so many similarities between English and French even though English is genealogically a Germanic language and French a Romance language. In this representation, languages grow and branch and spread out but evolve vertically following internal principles, as if this were the only "natural" way. In fact, this is a rather 19th-century, Eurocentric idea. It seems to reflect monolingual transmission as an ideal and prerequisite for preserving the purity of languages, but it is one that implicitly lives on in the notion of a mothertongue speaker as the ideal model. Language contact is in fact not rare and linguistic purity not a feature to be expected in plurilingualism, while languages themselves are historical constructs (Makoni \& Pennycook 2012).

\section{A multilingual linguistic sign}

There are two more trees to be examined here. One alludes to Saussure's (1916) iconic model of the linguistic sign consisting of a signifier and a signified, a sound shape and a meaning, with no necessary or logical link between them, illustrating the arbitrariness of the linguistic sign. While Saussure used the Latin arbor as a place marker for the sound shape, the poster's bold and playful adaptation tries to signal multilingualism by using Romansh, German, Italian, French and English signifiers for the signified represented by the image of the tree. Because of arbitrariness, different languages have different words for the same meaning. At the same time, there seems to be a conceptual gap in linguistics hinted at by this de-familiarization of the structuralist icon, which might be worth rethinking. Structuralism based the linguistic sign on the idealisation of a homogeneous speech community that shares one language and through convention determines what a word means, but the representation in Figure 4 adds words from different languages to the meaning (as might happen when languages are in contact).

While this adaptation suggests that every language has one word for the same overlapping meaning and that the words are translation equivalents, in fact such a correspondence is the exception rather than the rule. It mostly works for nouns, if at all, and then mainly for some natural kinds and for specialized terminologies. Usually, we have several words to choose from to render a meaning in another language, and we have to consider linguistic and situational context, word partnerships, and meaning relationships. Often, the meaning extensions themselves do not overlap between languages, e.g. the Romansh 


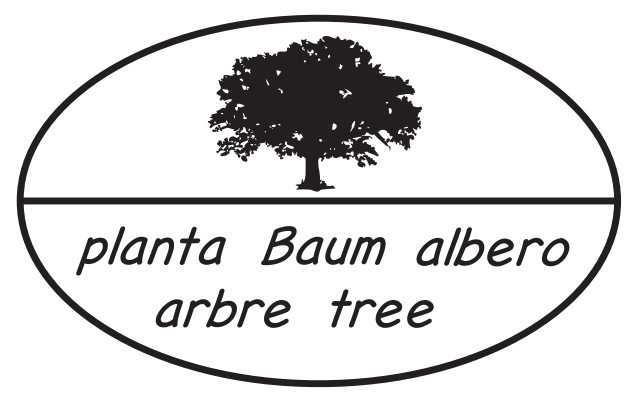

Figure 4: A multilingual linguistic sign.

word la planta means 'tree' but also 'plant'. In the mind of an individual, language contact can mean that different concepts dynamically influence each other, even affecting the concepts developed through the form-meaning mappings of the first language (e.g. Pavlenko 2009).

In psycholinguistic terms the construct of a multilingual lexicon (de Bot 2004) has more to do with language processing in plurilingual speakers than with translation equivalents. How are words from different languages accessed or retrieved, and how do they interact with each other, i.e. how is competition between them managed and what effects may this have on comprehension and production? How (fast) do we control and select languages if we cannot switch them on and off at will, for a large number of receptive lexical studies indicate that access to words is non-language-selective. What other findings suggest, however, is that the level of activation in different sets of the multilingual lexicon has an impact on the time factor, which in turn depends on such variables as the type of task performed or the level of proficiency in the languages involved or perhaps the method of instruction in this language. Little used words from a language that is not activated frequently are not likely to be competitive. There is agreement overall that multilingual language processing takes more time, especially in one's weaker language(s), but also that what is usually referred to as code-switching can be costly, particularly in terms of inhibiting one's stronger language. What is often used is more readily activated and therefore more difficult to inhibit, but once deactivated, it will be more difficult to rekindle activation. There is no switch in code-switching, so what do we do to actively produce in a weaker language, a language with a lower level of activation? There is no generally accepted answer to this question yet. What we are actually doing is, according to de Bot (2004), rather like holding down pingpong balls with our hands in a bucket of water: from time to time one of them will escape and pop up. 


\section{The syntactic tree diagram}

Unsurprisingly given its central stance of innateness, the Chomskyan paradigm shift in 20th-century linguistics nowadays reverberates more in computer science than in language teaching, though it does live on in some of our assumptions about language learning, for example that foreign language instruction should start as early as possible to be effective (for a critical examination, see Lambelet \& Berthele 2014). Instead of language being behaviourally conditioned by stimulus-response learning, in the Chomskyan paradigm language was regarded as innate, something that humans are biologically endowed to develop, a cognitive capacity we are hard-wired for: although children are exposed to only a finite number of sentences when acquiring their first language they develop grammars capable of creating an infinite number of novel grammatical sentences. All they need is for certain parameters to be set in time for the specific language to develop naturally, while delayed exposure to a language will lead to non-native features. The parameter which is said to be most sensitive is the phonological one, preventing the development of native-like accent after adolescence. Another assumption that is tied to Chomskyan linguistics is that native speakers of a particular language all have the same flawless grammatical intuitions and command of their language. The folk belief that native speakers are not only ideal informants but ideal language teachers is still widespread.

For the listener, sentence constituents and syntactic parsing do not seem immediately relevant when language comes at one in real-time, when one tries to understand a string of words that is gone before one can grasp it in the transient moments of lived plurilingualism. So what is the use of syntactic analysis (Figure 5)? University students are used to abstractions, and often bring highly developed grammatical notions from their previous language learning experiences. The foreign language classroom should be a place for focusing on a structure if this is helpful to learners in ultimately making sense of how words hang together. This can compensate for lack of recurrent exposure or complement it so that patterns become salient enough for noticing. This is not to argue that syntax actually exists as an autonomous language area, but to suggest that we may not need to rely exclusively on words and how they keep each other company in language teaching.

Let me add that the example sentence in Figure 5 was chosen not only for convenience and syntactic simplicity but also to instigate discussion about its message. Not everyone involved with university language teaching will be able to identify with We teach languages for academic purposes. Can one claim to be 


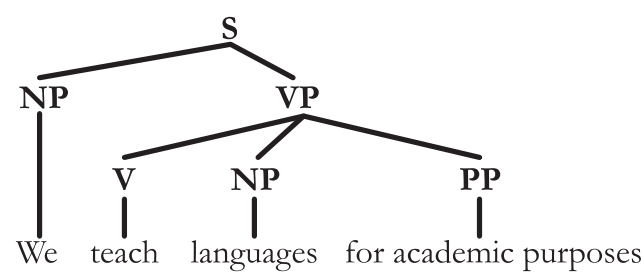

Figure 5: A syntactic tree.

teaching beginners for academic purposes? Based on the evidence of available teaching materials and on personal experience one must admit that there are severe limitations and frustration all around. What we can try to do, however, is to set our teaching parameters to meet the needs of literate adult learners with academic ambitions. What they are required to do in the target language at the university and in the linguistic landscape in which the university is located, and what they bring to the learning experience from their other languages and from their academic disciplines, can inform our pedagogical support until they are ready for language teaching for academic purposes in the usual sense.

\section{The Babel fish}

Anyone who looks at the MIS 10 building from afar will understand why it has been nicknamed the 'Aquarium'. However, this is not the whole story about the fish in the picture. In fact, it is connected to a work of fiction, The Hitchhiker's Guide to the Galaxy, by the British novelist Douglas Adams. There we read:

The Babel fish is small, yellow and leech-like, and probably the oddest thing in the Universe. It feeds on brainwave energy received not from its own carrier but from those around it. It absorbs all unconscious mental frequencies from this brainwave energy to nourish itself with. It then excretes into the mind of its carrier a telepathic matrix formed by combining the conscious thought frequencies with the nerve signals picked up from the speech centres of the brain which has supplied them. The practical upshot of all this is that if you stick a Babel fish in your ear you can instantly understand anything said to you in any form of language. The speech patterns you actually hear decode the brainwave matrix which has been fed into your mind by your Babel fish. [...] Meanwhile, the poor Babel fish, by effectively removing all barriers to communication between different races and cultures, has caused more and bloodier wars than anything else in the history of creation. (Adams 1979: 49f)

The representation of the Babel Fish seen on the poster was adapted from the one developed by the $\mathrm{BBC}$ for their TV series of The Hitchhiker's Guide to the 
Galaxy (the image is downloadable from http://www.bbc.co.uk/cult/hitchhikers/gallery/guide/babel1.shtml). The name may actually be more familiar from the internet machine translation tool originally on Altavista and now on Yahoo, though it derives from Douglas Adams's fictitious creature, which the characters in the novel insert into their ear to understand other species when crossing language divides during space travel. The name Babel fish also alludes to the biblical Tower of Babel. In fact, however, the Babel fish reverses the effects of what is described in Genesis as the confounding of language. Apart from the disastrous consequences for Adams's Galaxy, there are less far-reaching but also unpleasant consequences if internet translation devices are used for written assignments.

What is of note in the language metaphor implied here is that language consists of brain waves. The Babel fish enables communication by decoding nerve signals from speech patterns into conscious thought, reminding one of a widespread model of communication. What seems even more striking perhaps is that communication as the instantaneous understanding of incoming mental frequencies in the comedy sci-fi novel has come to stand for a popular view of translation. This idea, that comprehension equals translation, is one that many learners bring to the university language classroom. It is worth exploring and questioning as it does not favour direct access to meanings. Comprehension as translation is also misleading in that it equates a receptive skill with a (specialist) productive skill and overlooks the fact that we can often comprehend a great deal more than we can produce. It is also important to maintain this distinction when raising awareness of and promoting plurilingualism as a functional process that exploits and develops whatever linguistic resources and skills are available. In this way we acknowledge the asymmetries, partial skills and dynamic fluctuations of plurilingual repertoires, instead of assuming that plurilinguals "have" complete languages from or into which they can translate on demand. Plurilingualism does not equate to multiple monolingualism (Grosjean 1989): the resources and skills that constitute a plurilingual repertoire are not symmetrical, and comprehension in a target language does not require translation into a previously acquired language.

\section{The speech bubble}

The speech bubble (Figure 6) derives from the one on the cover of Nunan's (2012) book What is this thing called language? It reflects the core principle of 20th-century language studies that speech is primary, which to some extent motivated the 


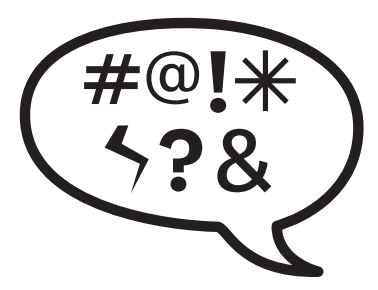

Figure 6: The speech bubble.

introduction of audiolingual methods in language teaching. Language certainly is speech, but for highly literate language learners, for university students who spend a lot of time reading silently and orthographically (processing words visually on the basis of their spelling, perhaps without recourse to target-language phonology), it may not be primary any more (see, e.g., Cook 2001, 2005). On the contrary, speech is what is often missing, and speaking aloud is likely to be the most difficult mode of functioning in an additional language in academia. Perhaps this is due not only to the challenges inherent in classroom discourse and academic public speaking but also to the influence of language socialization and language use experienced outside the university and in the dominant language. Texting, linking, liking, buzzing and posting on social media are to some extent replacing speaking as a way of reacting spontaneously to one's peers or to news that one comes across. Are some speech acts becoming gestures in terms of mouse clicks or key strokes?

What about the content of the speech bubble? It can come across in two ways. Either it stands for what we do not understand when someone talks to us in an unfamiliar language, in which case we may be tempted to avoid what we do not understand. Or we try to read the speaker's intention despite the different symbols, using what we know to make meaning. Here, the following interpretation might work. The hash tag is familiar from social media, where it has a variety of meanings. In linguistics, it stands for morpheme boundaries and might signal the compositionality of words and sentences. The @ symbol is used not only in email addresses but as a transcription symbol for laughter, which can signal embarrassment, agreement, humour, or relief in an utterance and assumes special functions in additional language use. The exclamation mark for emphasis can be used to indicate the pragmatic illocutionary force or communicative intention of an utterance, i.e. the effect it is supposed to have on the listener. The asterisk is a symbol for ungrammatical features, which occur not only in learner language but also in non-standard varieties of a language. In both situations, ungrammatical features may function as markers of 
accommodation, of covert prestige or of geographical affiliation. The S-flash looks like something from a comic book and may remind us of the importance of emotion. Despite the cooperative principle that shapes a lot of additional language use there can be conflict, which is even more difficult to resolve in an additional language than in a first language. It also reminds one, however, that swear words are often particularly interesting for learners and users of multiple languages (cf. Dewaele 2010) and can work as desirable in-group identifiers. Positive or negative emotion has more of a role to play in foreign language learning and teaching and additional language use than universities usually allow for. Finally, the question mark can stand for syntactic questions, which may be difficult to form in the target language, or for requests, either for information or action. Perhaps the ampersand (\&) could be interpreted simply as an addition or an overlap with the next utterance. Turns are usually followed by other turns, which is why leave-taking and signing off, or greetings and ways of managing the floor (who gets to speak first or next), are so important.

\section{The IPA cardinal vowel quadrilateral}

Cardinal vowels are not the vowels of any particular language. Rather, they are extreme abstract reference points to enable description and comparison, e.g. across languages. The geometrical shape of the outer lines, the vowel quadrilateral, is an idealisation of a space in the mouth along whose dimensions the tongue moves horizontally and vertically, i.e. from front (left side) to back (right side) and between close (up) and open (low), when producing vowels. The cardinal vowels can be numbered starting at the top left, but in Figure 7 they are identified by the labels of the International Phonetic Alphabet. More often than not one can see pairs of symbols, e.g. to the left and the right of a blob at the intersection of lines. Following the conventions of the International Phonetic Association, in the pairs displayed the phonetic symbols to the left are the primary cardinal vowels produced with spread or neutral lips, while those to the right are rounded vowels. It must be borne in mind that even though this representation is a classic, it has come under attack as a "pre-Galilean" view of vowel space. According to Lindsey (2013), it would be preferable to plot cardinal vowels on a triangular or rounded V-shaped chart of vowel space and to use colour analogy (http://englishspeechservices.com/blog/thevowel-space/), but this is not the point here.

The purpose of the vowel quadrilateral is to drive home the importance of articulation, of the physical, bodily aspect of forming sounds, and to reinforce three more specific points. First, university students often seem to associate learning 


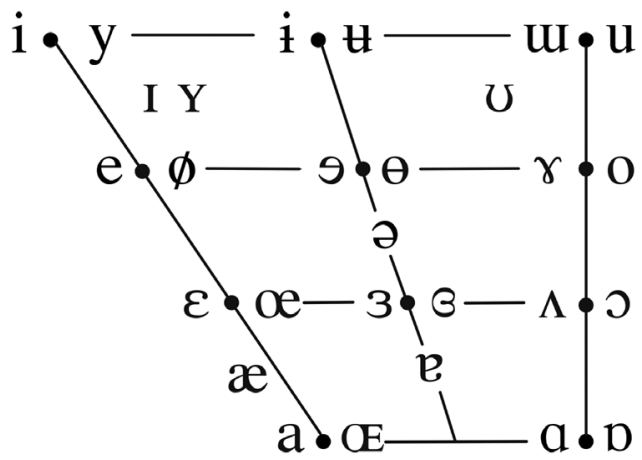

Figure 7: The IPA cardinal vowel quadrilateral.

(languages) with what happens in their heads. However, language is not only in the brain, it is in the body. Awareness of one's articulators or of movement in producing speech sounds is often limited to facial movement. One can learn to pay attention to the tongue, the roof of the mouth, the velum, the vibration of the vocal cords. Lips and teeth can be touched with one's fingers, but the further back inside the oral cavity something is, the trickier it can be to grasp, literally and metaphorically, what is going on when we pronounce. An aha-experience about the physical aspect of pronunciation can increase learner agency and self-efficacy in an area in which defeatism seems to be the rule. Secondly, because it can be a great challenge to hold transient real-time sequences of sounds in working memory, even if they are repeated, an alternative visual representation in the form of transcription symbols can help literate adults to work on their pronunciation. Thirdly, the vowel quadrilateral and the potential to visually locate where vowels are situated helps teachers understand that the location of vowels in one particular language in a plurilingual speaker varies systematically from the location of the "same" vowel in a monolingual speaker of the language (de Groot 2011) and that this need not cause problems as long as the meaning-distinguishing phonemic effects of the particular language can be maintained.

The vowel quadrilateral neither recommends that we should teach individual sounds before words and sentences nor implies that every learner needs what is still customarily called native-like pronunciation or that fluency requires learners to work on individual sounds. On the contrary, what fluency probably requires is syllables: fluency in a specific language may be a matter of activating its syllable subset (de Bot 2004), and activation of syllables may help to explain why individual sounds are not easy to access and change once fluency has been achieved. When whole syllables become activated, individual sounds often appear to be below or beyond what we can simultaneously pay attention to while speaking. 


\section{Concluding remarks}

There is room on a poster for only a few visual representations to stimulate discussion of plurilingualism, linguistic description, notions of learning and teaching, in short, conceptualisations that are influential for university language teaching. The most important recent insights from usage-based theories lend themselves least to being put on a poster: language not as a thing but as a process, or rather as "resource consolidation for future action ... emerg[ing] from process” (de Bot et al. 2013: 208, following Ellis \& Larsen-Freeman 2006 and Hopper 1998).

Neither the poster nor its discussion here claim that what is on the poster is actually what university language teaching is all about, but the notions displayed or alluded to all interface with my own reflective practice and my concerns as a university language teacher in a multilingual setting. They form part of a disciplinary knowledge base that is always developing and can only benefit from exchange.

University language teaching can enhance additional language development by providing windows of opportunity for purposeful linguistic engagement over an extended period of time. Such engagement is goal-oriented and can combine meaning making with attending to linguistic form; it can also develop awareness of the diversity of language conceptualisations and their implications. This does not mean applying linguistic theory but looking at real-world linguistic tasks, problems or dilemmas and examining them from the different vantage points that linguistic awareness and awareness of linguistic description and theoretical concepts affords us.

Making concepts and theories with a small $\mathrm{t}$ or a capital $\mathrm{T}$ explicit is important in institutional contexts in which people mean many different things when they use terms like language, bilingualism, and plurilingualism and even when they talk about individual languages. Swiss territorial conceptions of language use $^{3}$ and (general) pragmatic functional ones, ${ }^{4}$ communicative purpose and the purpose of language teaching, the ownership of languages and pedagogical goals, the protection of multilingualism or the protection of monolingualism, specific or academic purpose and linguistic hegemony, disciplinary and general language, language socialisation and language display, language of

3 Language use is seen as governed by the legal principle of territoriality and thus delineated by and in space (e.g. Coray 2004; Grünert 2012). It also corresponds to a widespread perception of the (Germanic-Romance) linguistic boundary as a concrete language border.

4 A functional perspective on language use is predicated on variably, negotiably and adaptably making meaning with one's linguistic resources (Verschueren 2009: 19-22). 
first contact and language contact: all these can become confused or inappropriately conflated. This, however, is "like attempting to unlock one thing with the key to something else" (Montgomery 2004: 1335) and might mean missing a valuable window of opportunity instead of availing oneself of it. What we hope we are doing, by contrast, is opening windows of opportunity for languaging, language learning and discussion.

Acknowledgements: I would like to thank Stefanie Neuner-Anfindsen, Acting Director of the Language Centre of the University of Fribourg, for commissioning this poster and providing the resources for its realisation, as well as for her comments on versions of the poster. Many thanks are due to Peter Sauter, Tisa Retfalvi-Schär, Anthony Clark, Ruedi Rohrbach, Barbla Etter, Jeannette Regan and Nikolaus Ritt for their hints or input. I am particularly grateful to Vinzenz Theodor Schaller for producing many versions of the formula in LaTeX and for the ideas he contributed to it. Sincere thanks are also due to the university's graphic designer Daniel Wynistorf, through whose expertise the poster was realized. The responsibility for any errors is of course entirely mine.

\section{References}

Adams, Douglas. 1979. The hitchhiker's guide to the galaxy. London: Pan Books.

Anderson, Lorin W. \& Lauren A. Sosniak (eds.). 1994. Bloom's Taxonomy: A forty-year retrospective. Chicago: University of Chicago Press.

Bloom, Benjamin S. (ed.). 1956. Taxonomy of educational objectives. Handbook I: Cognitive domain. London: Longman.

Borg, Simon. 2009. Introducing language teacher cognition. http://www.education.leeds.ac. uk/research/files/145.pdf (accessed 12 November 2014)

Brohy, Claudine. 2005. Overt bilingualism, covert multilingualism? Official languages and "other" languages in a bilingual French-German university. Paper presented at the "Bi- and multilingual universities: challenges \& future prospects" Conference. 1-3 September 2005, Helsinki University.

Butterfield, Ardis. 2012. Fuzziness and perceptions of language in the Middle Ages. Part I: Explosive fuzziness: The Duell. In Jeffrey M. Perl (ed.), Fuzzy studies: A symposium on the consequences of blur, special issue, Common Knowledge 18(2). 255-266.

Chafe, Wallace. 1994. Discourse, consciousness and time. The flow and displacement of conscious experience in speaking and writing. Chicago: University of Chicago Press.

Cook, Vivian. 2001. Knowledge of writing. International Review of Applied Linguistics 39. 1-18.

Cook, Vivian. 2005. Written language and foreign language teaching. In Vivian Cook \& Benedetta Bassetti (eds.), Second language writing systems, 424-441. Clevedon: Multilingual Matters.

Coray, Renate. 2004. Minderheitenschutz und Beziehungspflege: die Zweite Revision des Sprachenartikels (1985-1996). In Jean Widmer, Renata Coray, Dunya Acklin Musi \& Eric 
Godel (eds.), Die Schweizer Sprachenvielfalt im öffentlichen Diskurs/La diversité des langues en Suisse dans le débat public, 247-427. Bern: Peter Lang.

de Bot, Kees. 2004. The multilingual lexicon: Modelling selection and control. International Journal of Multilingualism 1(1). 17-32.

de Bot, Kees, Wander Lowie, Steven L. Thorne \& Marjolijn Verspoor. 2013. Dynamic Systems Theory as a comprehensive theory of second language development. In Maria del Pilar García Mayo, Maria Junkal Gutierrez Mangado \& Maria Martínez Adrián (eds.), Contemporary approaches to second language acquisition, 199-220. Amsterdam: John Benjamins.

de Groot, Annette M. B. 2011. Language and cognition in bilinguals and multilinguals: An introduction. New York: Psychology Press.

Dewaele, Jean-Marc. 2010. Emotions in multiple languages. Basingstoke: Palgrave Macmillan

Douglas, Scott. 2013. Pathways to production: Exploring lexical thresholds in speaking and writing. Keynote address, TESL Association of Ontario Annual Conference, Toronto, Ontario.

Ellis, Nick \& Diane Larsen-Freeman. 2006. Language emergence: Implications for applied linguistics. Applied Linguistics 27(4). 558-589.

Fischer, Andreas. 2010. Baum des Lebens, Baum der Sprache. Dies Academicus 2010 Address, Zürcher Universitätsschriften 12, University of Zürich. http://www.uzh.ch/about/portrait/ dies/2010/reden/UZH_Dies_Rede.pdf (accessed 15 November 2014).

Gamkrelidze, Thomas V. \& Vjaceslav V. Ivanov. 1990. The early history of Indo-European languages. Scientific American 262(3). 110-116. http://rbedrosian.com/Classic/sciam2. htm and http://rbedrosian.com/Classic/sciam1.htm (accessed 2 January 2015).

Gogolin, Ingrid. 1994. Der monolinguale Habitus der multilingualen Schule. Münster: Waxmann.

Gogolin, Ingrid. 1998. The "monolingual habitus" as the common feature in teaching in the language of the majority in different countries. Per Linguam 13(2). 38-49. http://perlinguam.journals.ac. $\mathrm{za} /$ pub/article/viewFile/187/298 (accessed 16 January 2015).

Grosjean, François. 1989. Neurolinguists, beware! The bilingual is not two monolinguals in one person. Brain and Language 36(1). 3-15.

Grünert, Matthias. 2012. Does the territoriality principle work in practice? The principle's applicability to the Romansh area in the Swiss canton of Grisons. In Andrea Ender, Adrian Leemann \& Bernhard Wälchi (eds.), Methods in contemporary linguistics, 463-486. Berlin: de Gruyter.

Herdina, Philip \& Ulrike Jessner. 2002. A dynamic model of multilingualism: Perspectives of change in psycholinguistics. Clevedon, UK: Multilingual Matters.

Hopper, Paul J. 1998. Emergent grammar. In Michael Tomasello (ed.), The new psychology of language: Cognitive and functional approaches to language structure, 155-175. Mahwah, N): Lawrence Erlbaum.

Hutton, Christopher. 2014. Racial and linguistic theories of human diversity in the context of National Socialism. Paper presented at the Colloquium on the History of Ideas on Multilingualism, 3-4 November, University of Fribourg, Institute of Multilingualism.

IPA (International Phonetics Association). 2005. International Phonetic Alphabet. https://www. langsci.ucl.ac.uk/ipa/IPA_chart_(C)2005.pdf (accessed 05 May 2014).

Jessner, Ulrike. 2006. Linguistic awareness in multilinguals: English as a third language. Edinburgh: Edinburgh University Press. 
Kaiser, Irmtraud, Elisabeth Peyer \& Raphael Berthele. 2014. Does different mean difficult? Contrastivity and foreign language reading: Some data on reading in German. International Journal of Bilingualism 18(3). 222-243.

Lambelet, Amelia \& Raphael Berthele. 2014. Alter und schulisches Fremdsprachenlernen. Stand der Forschung. Bericht des wissenschaftlichen Kompetenzzentrums für Mehrsprachigkeit. Institut für Mehrsprachigkeit. Freiburg, Switzerland.

Larsen-Freeman, Diane, 2009. Adjusting expectations: The study of complexity, accuracy, and fluency in Second Language Acquisition. Applied Linguistics 30(4). 579-589.

Li Wei. 2011. Moment analysis and translanguaging space: Discursive construction of identities by multilingual Chinese youth in Britain. Journal of Pragmatics 43(5). 1222-1235.

Lindsey, Geoff. 2013. The vowel space. Posted 27 March. http://englishspeechservices.com/ blog/the-vowel-space/ (accessed 03 May 2014).

Makoni, Sinfree. \& Alastair Pennycook. 2012. Disinventing multilingualism: From monological multilingualism to multilingual francas. In Martin-Jones, Marilyn; Adrian Backledge \& Angela Creese (eds.), Routledge handbook of multilingualism, 439-453. Abingdon, UK: Routledge.

Montgomery, Scott. 2004. Of towers, walls, and fields: Perspectives on language in science. Science 303 (27 February) Issue 5662: 1333-1335.

Mufwene, Salikoko. 2001. The ecology of language evolution. Cambridge: Cambridge University Press.

Nunan, David. 2012. What is this thing called language?, 2nd ed. Basingstoke: Palgrave Macmillan.

Pallotti, Gabriele. 2009. CAF: Defining, refining and differentiating constructs. Applied Linguistics 30(4). 590-601.

Pavlenko, Aneta (ed.). 2009. The bilingual mental lexicon: Interdisciplinary approaches. Bristol, UK: Multilingual Matters.

Pennisi, Elisabeth. 2004. Speaking in tongues. Science 303 (27 February) Issue 5662: 1321-1323.

Rajagopalan, Kanavillil. 2003. The philosophy of applied linguistics. In Alan Davies \& Catherine Elder (eds.), Handbook of applied linguistics, 397-420. New York: Blackwell.

Saussure, Ferdinand de. 1916 [1971]. Cours de linguistique générale. éd. Charles Bally et Alberte Sechehaye avec la collaboration de Albert Riedlinger. Paris: Payot.

Schaller-Schwaner, Iris. 2011. The eye of the beholder: Is English as a Lingua Franca in academic settings a monolingual or multilingual practice? Language Learning in Higher Education 1(2). 423-446.

Schaller-Schwaner, Iris. 2012. Researching English as a Lingua Franca and teaching English for Plurilingual Academic Purposes. In Blons-Pierre, Catherine (ed.) Apprendre, enseigner et évaluer les langues dans le context de Bologne et du CECR. Sprachen lernen, lehren und beurteilen im Kontext von Bologna und dem GER. Bern etc.: Peter Lang: 141-167.

Smith, Tom. 2014. The flipped pyramid and the snaggle-toothed edifice. Posted 5 January. http://eltcriticalmoments.wordpress.com/2014/01/05/the-flipped-pyramid-and-thesnaggle-toothed-edifice/ on http://eltcriticalmoments.wordpress.com/ (accessed 28 April 2014).

Stern, Hans Heinrich. 1983. Fundamental concepts of language teaching: Historical and interdisciplinary perspectives on applied linguistic research. Oxford: Oxford University Press. 
Swain, Merrill. 2006. Languaging, agency and collaboration in advanced second language learning. In Heidi Byrnes (ed.), Advanced language learning: The contributions of Halliday and Vygotsky, 95-108. London: Continuum.

Swain, Merrill, Sharon Lapkin, Ibtissem Knouzi, Wataru Suzuki \& Lindsay Books. 2009. Languaging: University students learn the grammatical concept of voice in French. The Modern Language Journal 93(1). 5-29. DOI:10.1111/j.1540-4781.2009.00825.x

Verschueren, Jef. 2009. Introduction: The pragmatic perspective. In Jef Verschueren \& Jan-Ola Östman (eds.), Key notions for pragmatics, 1-27. Amsterdam \& Philadelphia: John Benjamins.

\section{Bionote}

\section{Iris Schaller-Schwaner}

Iris Schaller-Schwaner has been teaching English at university level for more than 20 years, mostly as an EFL lecturer at the University of Freiburg/Fribourg Language Centre and the Department of Languages and Literatures, Multilingualism \& Foreign Language Education. Her current research focus is English as a lingua franca in multilingual academic contexts; she has also published on pedagogical grammar and English in Swiss billboard advertising. 